\title{
Las artes como narrativa histórica
}

\author{
The arts as a historical narrative \\ Emilce N. Sosa \\ Instituto de Historia del Arte \\ Facultad de Filosofía y Letras - Universidad Nacional de Cuyo-Argentina \\ emilcesosa@ffyl.uncu.edu.ar
}

\section{Resumen}

Nuestra propuesta tiene por objetivo abordar el estudio de las representaciones visuales latinoamericanas, como elemento fundamental en la construcción de las identidades.

Para ello fue necesario desarrollar una aproximación a partir de una construcción conceptual de las narrativas históricas, a través de fuentes no escritas. Las que nos permiten reflexionar en torno al discurso visual; desde la historia social y la historia cultural además, de otros abordajes como la memoria, la ideología, los imaginarios sociales y las representaciones colectivas, dentro del campo disciplinar histórico.

Palabras clave: representaciones, imaginarios, historia cultural.

\begin{abstract}
Our proposal aims to address the study of Latin American visual representations, as a fundamental element in the construction of identities.

For this, it was necessary to develop an approach from a conceptual construction of historical narratives, through unwritten sources. Those that allow us to reflect on visual discourse; from social history and cultural history in addition, to other approaches such as memory, ideology, social imaginaries, and collective representations, within the historical disciplinary field.
\end{abstract}

Keywords: representations, imaginary, cultural history.

Recibido: 10 de mayo $2021 \cdot$ Aceptado: 15 de julio 2021 


\section{Algunas aproximaciones metodológicas}

Articular históricamente lo pasado no significa conocerlo «tal y como verdaderamente ha sido». Significa adueñarse de un recuerdo tal y como relumbra en el instante de un peligro. (Benjamín, 1989: 180)

En función de la necesidad de comprender la construcción conceptual de las narrativas históricas latinoamericanas, será necesario poner en discusión todas las fuentes considerando a los objetos artísticos y a las representaciones visuales como elementos testimoniales, los que poseen una narrativa que permiten la construcción de la identidad y la memoria. Para ello el estudio será analizado desde los procesos historiográficos, relacionados con el uso de la imagen como narrativa histórica.

Hemos tomado en consideración algunos referentes, y de esta manera, hemos establecido un recorrido que nos permite situarnos en algunos fundamentos epistemológicos, a fin de lograr una aproximación en la construcción histórica, con el uso de la imagen como elemento testimonial.

Nuestro punto de partida será el siglo XX más precisamente, en 1929 cuando en París se publicó la Revista Annales d' historie èconomique et sociales, que dio origen a la corriente historiográfica conocida como la Escuela de los Annales. Esta corriente significó una serie de cambios específicos en la visión tradicional de la historia. La nouvelle histoire contribuyó y conformó una manera diferente de resolver problemas y enfoques metodológicos en el campo histórico. Entre sus contribuciones se distinguen diferentes formas de elaborar el relato histórico, a través de un abordaje desde el campo social, económico y de las mentalidades. Otro cambio significativo fue la interacción dialéctica entre el proceso histórico y la producción historiográfica de forma crítica (Sánchez Delgado, 1993: 322-325). Esta nueva forma de abordaje permitió un tipo de investigación más flexible y abierta, sobre todo en el uso de diversos tipos de fuentes. Ya que su objetivo fue crear una "historia total" integrando una compleja red de relaciones que constituyen las sociedades (Sánchez Delgado, 1993: 350-364).

La Escuela de los Annales en su desarrollo contó con varias generaciones de investigadores entre los que se destacan sus fundadores: Marc Bloch y Lucien Febvre. A partir de 1968 una nueva generación dio origen "a la denominada historia de las mentalidades" (Cano Vargas, 2012: 135) de la mano de historiadores como George Duby, Michelle Vovelle, Philippe Àries, Jacques Le Goff y Pierre Nora, entre otros. Esta tercera generación abrirá el campo histórico a ciencias y disciplinas provenientes de otras áreas como la antropología, la etnografía y "el arte"; a temáticas antes jamás abordadas por la historia como fue la muerte o la vida cotidiana. De esta manera, el campo disciplinar histórico abrirá su mirada hacia el campo mental y simbólico.

La tercera generación de los Annales extendió así sus horizontes hacia las ciencias sociales, desde una perspectiva sociocultural, de esta manera comenzarán a desarrollarse abordajes históricos que habían sido considerados hasta ese entonces como problemáticas marginales (Sánchez Delgado, 
1993: 403). Los Annales constituyó un cambio en la forma de construcción en la investigación histórica permitiendo explorar nuevas áreas del conocimiento, y de esta manera analizar los objetos de estudio en forma interdisciplinaria, rechazando la visión historiográfica tradicional. Este nuevo enfoque interpretativo de los significados sociales pone énfasis en la comprensión de las acciones humanas representadas a partir de su “símbología”. De esta manera, la importancia de estos estudios radica en la forma de su abordaje; es decir, a partir de un análisis histórico social de las representaciones colectivas, entendiendo que ésta

[...] se construye sobre la dialéctica relación pasado-presente y se concreta cuando la ciencia histórica se convierte, en un instrumento de conocimiento reflexión y crítica, en el marco conceptual indispensable para operar en el presente sobre los testimonios de la cultura material del pasado. (Burke, 1996: 56)

Sin embargo, las artes han sido estudiadas tradicionalmente desde la historia del arte como un hecho estético e histórico y desde una perspectiva "formalista-biográfica". Este análisis deja de lado el contexto de producción, ya que la obra de arte fue considerada por mucho tiempo, sólo como un elemento plástico cuyo valor residía en su materialidad. Aunque es importante considerar que la

[...] realización de una obra de arte es un proceso histórico más entre otros actos, acontecimientos y estructuras; es una serie de acciones en y sobre la historia. Es posible que sólo sea inteligible dentro del contexto de unas estructuras de significado dadas e impuestas, pero, a su vez, es capaz de modificar y a veces incluso de destruir estas estructuras. El material de una obra de arte puede ser la ideología (dicho en otras palabras, las ideas, imágenes y valores aceptados por todos). (Clark, 1981:13).

De este modo, y a partir de este enfoque surgió la necesidad de buscar nuevos abordajes, los que “[...] preocupados por producir una ruptura manifiesta con la focalización tradicional del binomio sobre arte" (Heinich, 2002:16).

Heinich, en sus estudios, establece una clasificación generacional dividida en tres etapas. La primera generación la define como la toma de conciencia estética, de tradición marxista en la que se destacan las figuras de Yuri Pleyanov (1912) quien otorgó las bases marxistas del arte. Entre otros referentes se destaca Francis Kinderger, Antal, Hauser, Hadjinicolau, entre otros. Otra línea que cuestionó la visión marxista fue la figura de Ernest Gombrich. Paralelamente a esta se desarrolló la escuela de Francfort, con Adorno y Benjamin que se alejan de la corriente marxista ortodoxa. Finalmente, Francastel (del arte a lo social), sostiene que el arte no es un reflejo de la sociedad, sino una construcción de "realidades imaginarias” (Heinich, 2002: 19-25).

En la segunda generación, durante los años cincuenta, los abordajes investigativos sobre arte comenzaron a utilizar métodos provenientes de la historia social, historia de las mentalidades, historia cultural entre otros enfoques, los que permitieron un abordaje sobre las problemáticas 
del "contexto-económico, social, cultural, institucional de producción o de recepción de obras" dichos métodos provenían del campo histórico como ya hemos mencionado. Y más allá de la tradición de la historia social del arte, se destacan Pevsner, Clark, Baxandall y en microhistoria Carlo Ginzburg, (Heinich, 2002: 28-41). Por último, la tercera generación el arte se interesará por "el arte en sociedad", entre sus referentes sobresalen Jakobson, Bastide entre otros destacados (Heinich, 2002: 43-45).

\section{Hacia una historia cultural}

Son relativamente pocos los historiadores que consultan los archivos fotográficos, comparados con los que trabajan en los depósitos de documentos manuscritos o impresos. Son relativamente pocas las revistas de historia que contienen ilustraciones, $y$ cuando las tienen, son relativamente pocos los autores que aprovechan la oportunidad que se les brinda. Cuando utilizan imágenes, los historiadores suelen tratarlas como simples ilustraciones, reproduciéndolas en sus libros sin el menor comentario. En los casos en los que las imágenes se analizan en el texto, su testimonio suele utilizarse para ilustrar las conclusiones a las que el autor ya ha llegado por otros medios, y no para dar nuevas respuestas o plantear nuevas cuestiones.

¿Por qué iba a ser así? En un artículo en el que describe su descubrimiento de la fotografía victoriana, el difunto Raphael Samuel se definía a sí mismo y a otros especialistas en historia social de su generación como «analfabetos visuales». (Burke, 2005: 12)

Es a partir de Perter Burke, que comenzaremos a tratar de entender cómo los estudios culturales son una producción determinada de relaciones sociales, donde las ideologías engloban comportamientos por los que se define al hombre, es decir que son representaciones propias de una época (Vovelle, 1985: 29-31). Por lo tanto, el análisis de las estructuras sociales postula una explicación de los comportamientos y de las actitudes colectivas, a través de sus representaciones, poniendo de manifiesto la vida real de los hombres y la imagen que se hace de ella (Vovelle, 1985: 18). Entre sus contemporáneos Jacques Le Goff y Pierre Nora sostienen que el estudio de

[...] la historia de las mentalidades no se define solamente por el contacto con las demás ciencias humanas y por la emergencia de un dominio reprimido por la historia tradicional. Es también el lugar de encuentro de exigencias opuestas que la dinámica propia de la investigación histórica actual fuerza al diálogo. Se sitúa en el punto de conjunción de lo individual con lo colectivo, del tiempo largo y de lo cotidiano, de lo inconsciente y lo intencional, de lo estructural y lo coyuntural, de lo marginal y lo general. (Le Goff y Nora, 1974)

De esta manera, podemos comprender que los investigadores han centrado su objeto de estudio en las actitudes mentales, entendiéndose también como imaginarios sociales. Estas visiones 
comprenden a las representaciones colectivas como imágenes inconscientes de una sociedad, las que son representadas a través de objetos, $\mathrm{y}$ apropiaciones culturales. En ellas se desarrolla, un complejo entramado de ideas como parte de una construcción social, los que han sido estructurados en base a un conjunto de imágenes y relaciones de imágenes, que el hombre construye en sociedad (Cano Vargas, 2012: 138). Durand propone que la "re-presentación simbólica, nunca puede confirmarse mediante la presentación pura y simple de lo que significa, el símbolo, y en última instancia, sólo vale por sí misma" (Durand, 1968: 15).

Por lo tanto, la imagen simbólica es una transfiguración de una representación concreta, con un sentido totalmente abstracto. De tal modo, las representaciones colectivas se desprenden de los estudios de los imaginarios sociales. Cano Vargas establece que existen dos grandes categorías de lo imaginario, en la que distingue a) las imágenes (de realidad física y mental) las que se encuentran en una sociedad representada por imágenes en fotografías o cartelería. Y b) la de los imaginarios (como sistema de representación) en las que se configuran prácticas y las creencias de los imaginarios sociales entendiéndose como formas ideológicas. (Cano Vargas, 2012: 141).

Sin embargo, las fuentes materiales poseen una carga simbólica que interactúa en un contexto determinado en una temporalidad concreta, y que a su vez se construye como testimonios visuales que ayuda en la reconstrucción de acontecimientos y de comportamientos sociales. Es responsabilidad del investigador el leer estas imágenes como relatos visuales o como testimonio histórico de una sociedad o una cultura. Esta visualidad es portadora de un discurso, no tan sólo por la polisemia de la imagen, sino porque estás, como afirma Burke fueron en su mayoría creadas para desempeñar múltiples funciones sociales, como las imágenes estéticas, políticas y narrativas entre otras (Burke, 2005: 236). Burke les asigna un valor a las imágenes, como fuentes documentales y elementos testimoniales para la construcción de la historia, apoyándose en la ventaja comunicacional que poseen éstas, además de la rapidez y la claridad en su relato (Sánchez Delgado, 1993: 101). Las imágenes “... pueden revelar o implicar con respecto a las ideas, actitudes y mentalidades durante las diversas épocas" (Sánchez Delgado, 1993:100). Por otro lado, es fundamental comprender que las imágenes registran diferentes formas de comportamiento social, entendiéndose como construcciones y testimonio de imágenes mentales. Además, no se debe olvidar su alto grado de idealización o de sátira que pueda contener a través de sus narrativas discursivas (Sánchez Delgado, 1993: 146-182).

Un ejemplo de ello lo vemos a continuación con la obra de James Gillray de 1805.

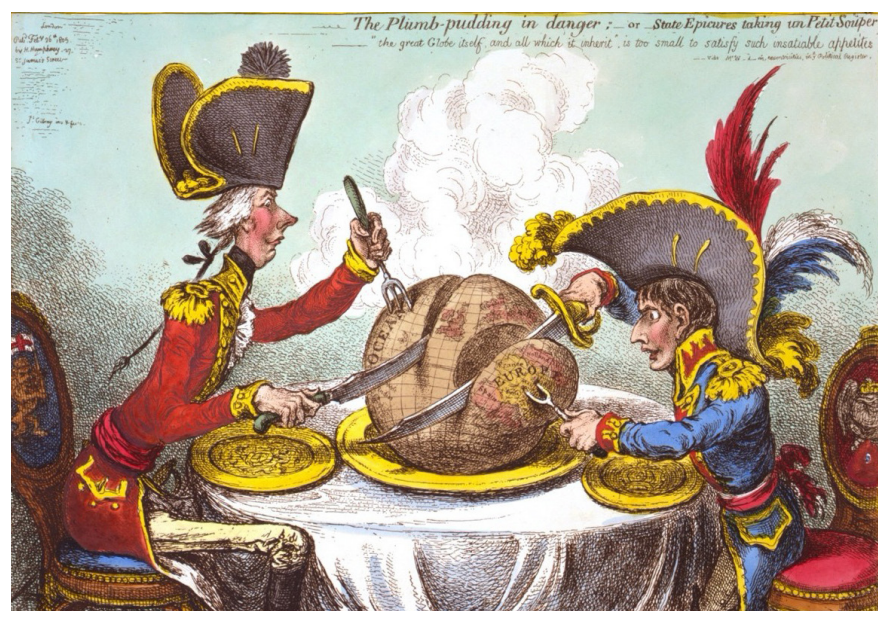


Fig. 1- Los personajes de la obra son el Priemer Ministro británico William Pitt y el reciente Emperador de Francia Napoléon Bonaparte en: En web: https://www.bl.uk/collection-items/ the-plumb-pudding-in-danger---or---state- epicures-taking-un-petit-souper-by-gillray, [consultado 2021]. Uso y dominio de la imagen: público.

Autor: James Gillray 1756-1815 (de The Caricatures of Gillray) Título: "El pudín de plomada en peligro - o - Epicures estatales tomando un Petit Souper"

Técnica: Aguafuerte coloreadas a mano Fecha: 1805 Publicado: aprox. 1818 en Londres La descripción de la obra:

James Gillray fue uno de los mejores caricaturistas del período georgiano. Primero aprendiz de grabador en Londres, Gillray intentó lanzarse como artista convencional al estudiar en la Royal Academy School. Pero fue en la caricatura donde Gillray encontró su verdadera vocación. Se cree que publicó más de mil sátiras durante su vida, llamando especialmente la atención por su ridiculización de George III, la familia real, Napoleón y la Francia revolucionaria. "El pudín de plomada [sic] en peligro" es una de las sátiras más famosas de Gillray sobre las guerras napoleónicas de principios del siglo XIX. El primer ministro británico, William Pitt, se sienta a la izquierda de la imagen frente a Napoleón Bonaparte, quienes rasgan hambrientos al mundo en un intento por ganar una porción más grande. Aunque la intención de la pieza es simple (haciendo el ridículo la búsqueda avariciosa del dominio internacional por parte de los gobiernos francés y británico), la representación grotesca de los personajes de Gillray de repente da vida a la caricatura. Nótese particularmente la exageración del físico flaco de Pitt y la nariz con forma de pico de Napoleón: dispositivos cómicos que habrían identificado rápidamente los temas a su audiencia al apelar a las concepciones populares de los dos hombres. (Biblioteca Británica, 2019).

Hadjinicolaou propone un análisis concreto de las imágenes considerando que “... un período históricamente determinado requiere el conocimiento de todos estos términos, para estar en situación de reconocerlo en la realidad histórica" (Hadjinicolaou, 1974: 11); estas apreciaciones determinan que la ideología tiene por función en algunos casos, disimular las argumentaciones reales y reconstruir sobre un plano imaginario, un nuevo discurso coherente, insertándolas en una unidad de relaciones en formación. Porque esta comprende elementos dispersos del conocimiento, procesos de simbolización y de abstracción, es decir, todo tipo de relaciones sociales, donde se ponen de manifiesto el modo de vida social (Sosa, 2015: 223). De este modo, la lectura que realiza Hadjinicolaou establece que

La significación de una obra" no está en la obra: no es sino la explicación que se da de ella y que se cree o se pretende haber descubierto en las profundidades invisibles de ésta”. Por eso nunca puede hablarse de significación en sí o de significación intrínseca de una obra sino de significaciones coexistentes que se 
siguen y se oponen en el tiempo. (Sánchez Delgado, 1993: 121)

Esta diferencia permite destacar la obra de su actualidad cambiante con el tiempo y su relación con el pasado artístico (Sánchez Delgado, 1993: 133-159), de alguna manera es un planteamiento crítico a los postulados de Panofsky, al rechazar su método a partir de los diferentes niveles de significación que considera: un significado primario y natural, subdividido a su vez en otro fáctico y expresivo; una significación secundaria y convencional, y finalmente una significación intrínseca o de contenido (Panofsky, 1983:43-49). En función de estos tres niveles Burke critica al método iconográfico el que considera un exceso de intuición y de especulación, y por lo tanto es un método subjetivo que carece de dimensión social, por ser indiferente al contexto (Burke, 2005: 50-51).

Por otro lado Hadjinicolaou afirma

[...] otro problema relacionado a su vez con dos tipos de ideologías: una ideología tipo social (el reconocimiento de ese hecho implicaría el reconocimiento de la existencia de las clase sociales y de sus intereses conflictivos) y de ideología de tipo «científico» (la creencia en una ciencia histórica pura que revela la Verdad, lo cual corre parejas con la convicción de que una construcción del pasado "tal como era realmente" es posible si se logra evitar la contaminación por ideas, preocupaciones e intereses del presente).

Ésas son todas las razones por las que hay que abandonar la búsqueda de la significación intrínseca de la obra y considerar el análisis del conjunto de sus significaciones (para el artista que produjo, para el público al cual fue destinada y para los públicos posteriores). La elección del tema y el método empleado, así como actitud del autor con respecto a la obra, tendrán como resultado colocar el producto final de esa investigación como elemento de una tendencia contemporánea de la historia del arte. (Sosa, 2015: 218)

A lo que Burke señala, que es importante comprender el significado de las imágenes dependiendo de su "contexto social" teniendo en cuenta el ambiente cultural, político, además de las circunstancias concretas en que se produjo el encargo o el "contexto material" en el que se inscribe, y el escenario físico en que originariamente fue contemplada. En la construcción de las imágenes de carácter artísticas, es importante destacar que se deberá tener en cuenta el uso de las convenciones artísticas (académicas o no), como parte de su producción.

Pero, como nos lo enseña la dialéctica tradicional, la operación historizadora puede seguir dos caminos distintos, que sólo en última instancia se encuentran en un mismo lugar: el camino del objeto y el camino del sujeto, los orígenes históricos de las cosas mismas, y esa historicidad más tangible de los conceptos y las categorías por cuyo intermedio intentamos entender esas cosas.

[...] y algo bastante diferente que pondría en cambio en el primer plano las categorías interpretativas o códigos a través de 
los cuales leemos y recibimos el texto en cuestión. (Jamenson,1989: 11)

Y a partir de esta discusión Burke manifiesta la utilización de métodos contrapuestos, pero a su vez complementarios. Ya en 1996 establecía la necesidad de un abordaje interdisciplinario a través de nuevos postulados como estudios feministas y no necesariamente en los términos exclusivos de clases sociales, sino desde un análisis del estudio de género los que hoy son abordados con mayor fuerza. Además, propuso una aproximación a las teorías de la recepción, abordadas a través de las respuestas dadas a las imágenes a lo largo de la historia, y en paralelo hacia las tendencias surgidas por los estudios literarios. Por lo tanto, el testimonio de una imagen o de una obra de arte debe ser situado en un contexto: "cultural, político, material, de género y de clase, como así de las convenciones propias que rigen las representaciones en un momento determinado" (Burke, 2005: 227-239).

Entre otros historiadores que abordaron temas relacionados con las artes encontramos en la cuarta generación de la Escuela de los Annales, la figura de Roger Chartier (2003), que aborda la noción representación y del tiempo. Su propuesta gira alrededor de construcciones narrativas, entendiéndose como el contenido lógico de una idea con características simbólicas ya que es una construcción en sí misma, y tiene un lenguaje propio. Posee un texto abierto dinámico e implícito, el que puede ser comprendido a través del espacio y del tiempo. Además interacciona con su contexto, ya que puede representar una realidad. Es decir: la necesidad de discutir conceptos y categorías de análisis como la apropiación, aculturación, representación capaces de desplazar nuestro conocimiento del pasado y fundar una visión más lúcida de los tiempos en que vivimos (Chartier, 2003: 15).

Estas lecturas aportarán nuevas formas de interpretación, a partir de una reflexión epistemológica sostenida a la crítica a las mentalidades que se desarrollaron en 1980. Así la historia cultural analizará junto con otras Ciencias Sociales estas representaciones que postula Chartier, como un instrumento de conocimiento mediato, que permite una conceptualización del objeto (ausente) y sustituirlo por una imagen capaz de volverlo a la memoria (ya que estas son las representaciones sociales inconscientes que poseen múltiples dimensiones que permite construir la historia). Estos imaginarios son instrumentos de percepción de la realidad social "construida", de tal manera los "imaginarios sociales" forman parte de una construcción social, política religiosa y a su vez se encuentran representadas en imágenes las que poseen interacciones, apropiaciones, intenciones, circulación y sobre todo objetivos sociales.

Por otro lado, Weltanschauung es un término que alude a:welt, "mundo", y anschauen, "observar", éste fue utilizado por Dilthey (1954), donde su concepto filosófico se comprende como aquellas percepciones o conceptualizaciones del entorno de un sujetoy de este modo se las reconoce como “cosmovisión”. Se puede establecer que éstas son realidades físicas como un elemento material y objeto cultural, los que representan una fuente documental no escrita. Finalmente, las 
representaciones mentales representan "ideas" como sistema en las que surgen creencias y prácticas socioculturales, de esta manera podemos comprender a estos conceptos, a partir del análisis que realiza Bourdieu cuando cita a Baxandall afirmando que "la mayor parte de las costumbres visuales de una sociedad no está naturalmente registrada en los documentos escritos" (Bourdieu, 2010: 241).

\section{Algunas consideraciones hacia las representa- ciones visuales Latinoamericanas}

Nos propusimos desarrollar la comprensión de las narrativas en el arte Latinoamericano, pero al abordar esta problemática entendemos que se hace necesario comprenderla desde sus propias individualidades. Así, teniendo en cuenta algunos conceptos elaborados por Andrea Guinta, cuando nos plantea, que se debe tener cuidado en las denominaciones para evitar caer en reduccionismos y vaciamientos de los rasgos característicos y específicos de cada una de las diferentes sociedades y culturas de América Latina. Sin dejar de considerar el gran entramado étnico, social y cultural del continente, y de esta manera poder abordar clara y sustancialmente las características históricas propias que dan origen a las conductas identitarias (Guinta, 1996: 1-5).

Desde los primeros años de vida institucional en la Argentina surgen relatos que serán la base de una idea de nacionalismo que dará origen a una construcción de la arquetipo de historia nacional.
A su vez, estos ideales permitieron forjar y concretar las bases de la historia del arte argentino (Malosetti Costa; Siracusano y Telesca, 1999: 395) a partir de narrativas, que fueron desarrolladas a través de un discurso sostenido, con la utilización de objetos y artefactos portadores de elementos simbólicos, entre los que se destacan: imágenes, emblemas, escudos, además de otros tantos objetos que permitieron establecer la aceptación social como elemento de identificación del nuevo Estado Nacional y como construcción identitaria (Sosa, 2019: 3).

Estas estructuras de identificación serán el punto de partida para el fundamento de las memorias locales que, en el caso de la Argentina surgirán a través de los trabajos de historiadores como Eduardo Schiaffino, considerado el primer historiador del arte. Su obra más representativa es La pintura y la escultura en Argentina (1783-1894), publicada en 1933, aunque uno de los primeros textos que aborda el arte argentino fue realizado por José María Lozano Mouján con su obra: Apuntes para la historia de nuestra pintura y escultura publicado en 1922.

Al abordar algunos conceptos de Eduardo Schiaffino comprendemos su análisis a favor de las posibilidades de un "arte latinoamericano", sosteniéndose frente al peso de la tradición europea (Malosetti Costa, 2002: 9). De esta manera, y a partir de estas opiniones la historiografía del arte argentino permitió y contribuyó a la construcción de un ideario nacional a través de sus héroes (Malosetti Costa, 2002: 11). 
De este modo proponemos una visión crítica de la política decimonónica y su vinculación con la sátira impresa ilustrada que se desarrolló en la argentina. De tal modo, que el arte se pondrá de manifiesto a través de diferentes formas discursivas originales y coherentes acompañado de una gráfica mordaz. Los procesos artísticos desarrollados a través de estas imágenes convirtieron a los periódicos en "máquinas de guerra" (Román, 2010: 327), con un discurso coyuntural crítico correspondiente a la conformación de un estado nacional. Estas publicaciones surgirán en medio de conflictos sociales y culturales. Su narrativa se basó en figuras y personajes que dan cuenta de hechos y circunstancias del contexto nacional, transformándose en un registro documental gráfico de la política argentina. Su finalidad fue estar destinada a sectores populares y, en muchos casos, siendo estos grupos analfabetos, a través de las imágenes exhibidas en los escaparates de negocios, éstos podían entender los sucesos acaecidos. Algunos de los antecedentes de la sátira política son provenientes (provienen) del período colonial, los que son conocidos como pasquines. Estos eran dibujos satíricos de tipo caricaturesco que se realizaban en una especie de volante anónimo, con una fuerte crítica.

Existieron diferentes tipos de pasquines. Entre ellos se destacan los de prosa y los de verso con una crítica dirigida hacia las autoridades coloniales y, los pasquines con imágenes para la población local, los cuales, a través de una lectura de la imagen se podía entender su contenido de forma sencilla, ya que poseían características netamente alusivas.

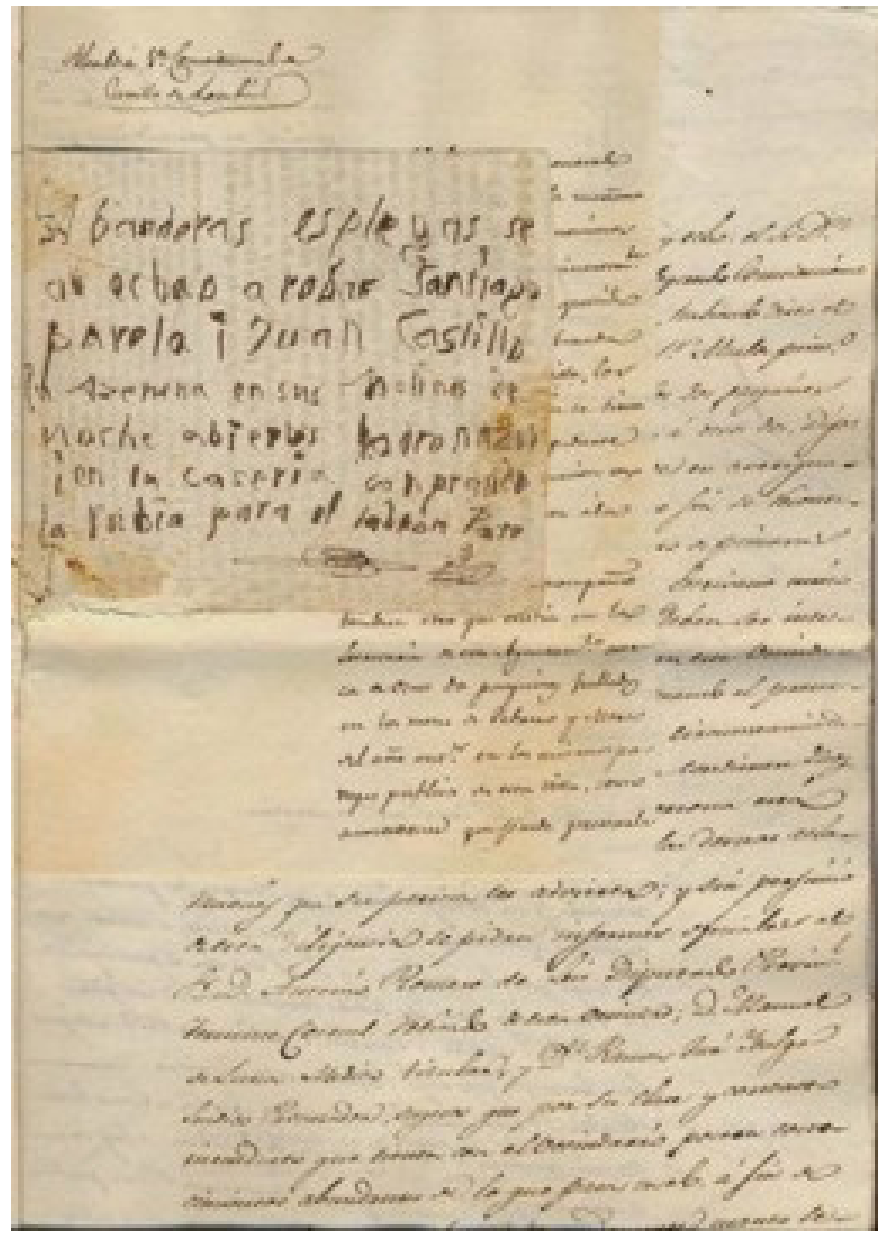

Fig. 2- Pasquín, en: Pasquines del Perú, recuperado de: http://historiaperiodimosenelperu.blogspot. com/2014/11/los- pasquines-en-el-peru-siglos-xviii-y.html [consultado 2021] 


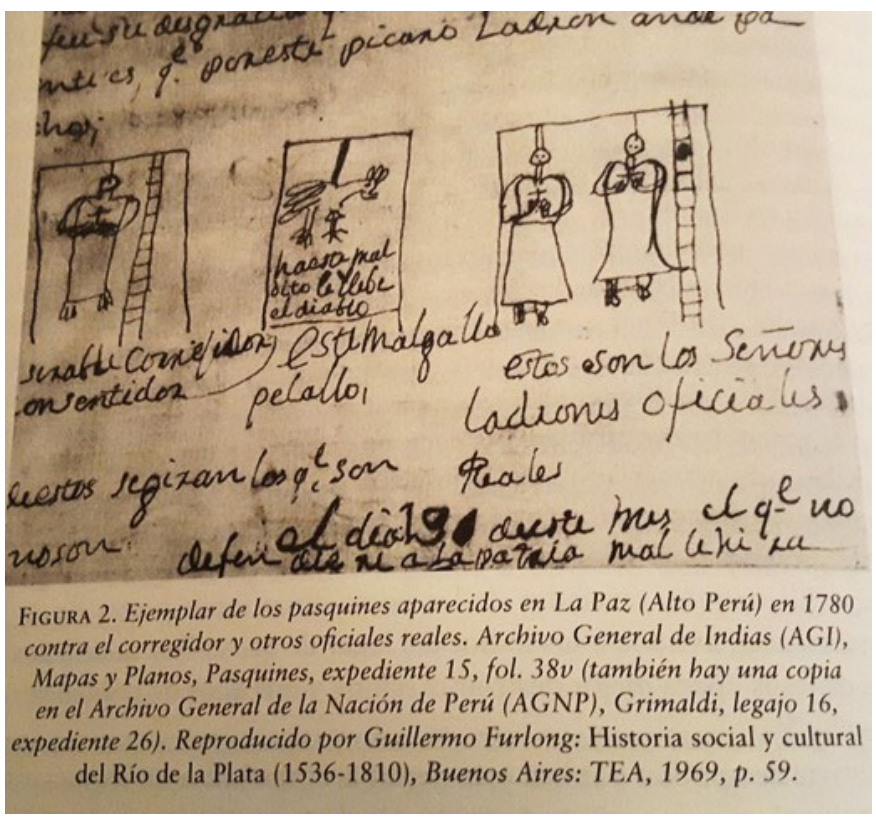

Fig.3- Pasquines en la ciudad de la Paz, en 1780 contra el corregidor y oficiales reales, con motivo del cobro de la alcabala para la Aduana. pasquines de la Paz - Arequipa (Perú). Archivo General de Indias, Mapas y Planos- Pasquines, 15, Sevilla, España, recuperado de: https://media.timetoast. com/timelines/origen-y-desarrollo-de-la-prensa [consultado 2021].

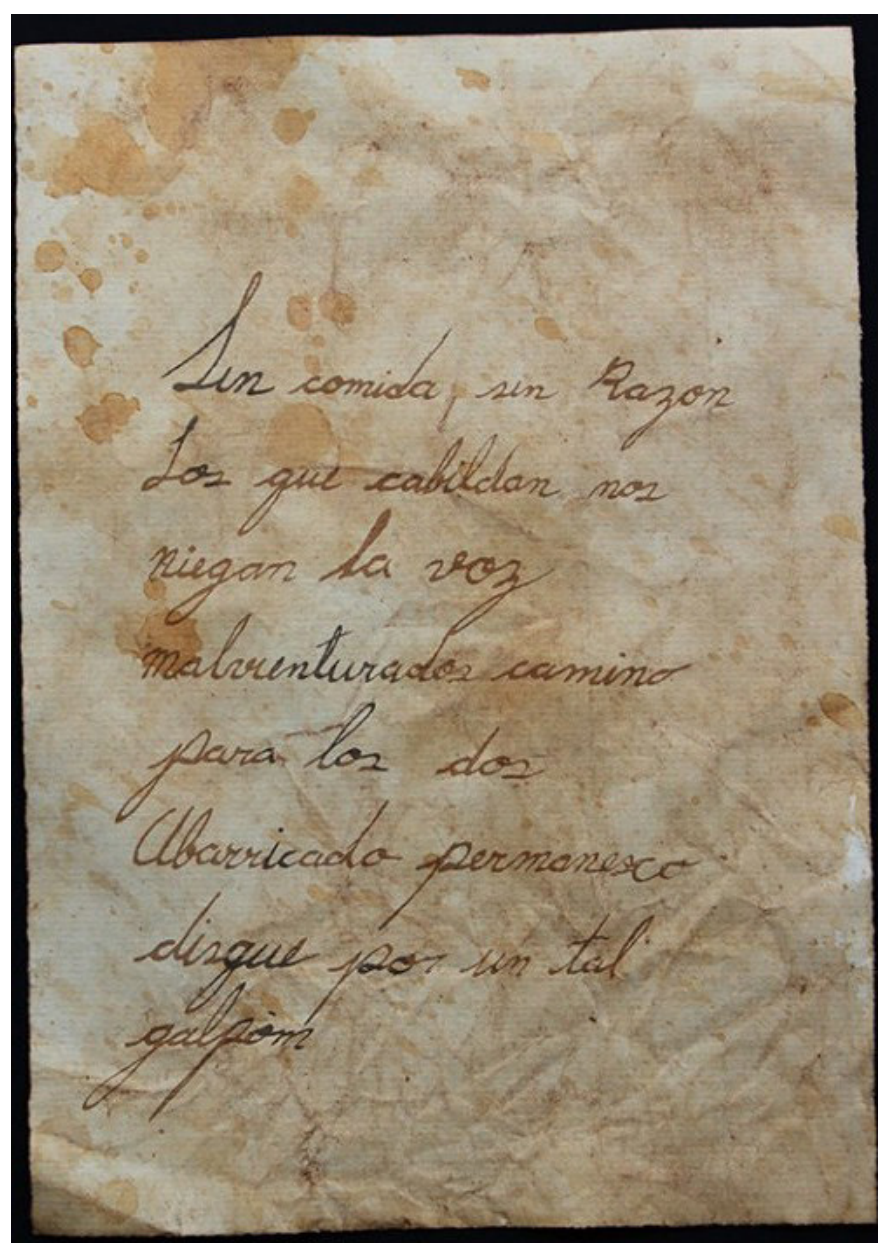

Fig. 4- Pasquín colombiano, período independiente, recuperado de: Pasquines, web: https:// perezia.wordpress.com/2019/02/05/pasquines-libelos-y-demas-verdades/, [consultado 2021].

Entre las publicaciones, de la gráfica política editada en Buenos Aires encontramos diferentes obras como por ejemplo en 1828, El hijo del negro del diablo rosado, luego en 1835 Blacke, prensa litográfica, en 1863 comienza la publicación de: El Mosquito, en 1884 Don Quijote y finalmente en 1891 Caras y Caretas. Estas publicaciones fueron críticas mordaces, sus imágenes se convirtieron en narrativas políticas en las que se exponían 
figuras y personajes. Pero, sobre todo, daba hechos concretos de la realidad política argentina.

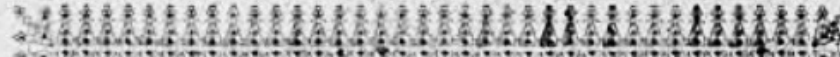

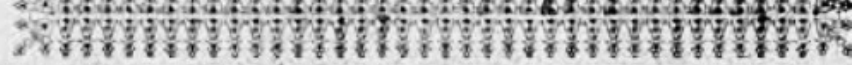 A DEMOCRITO \\ Con motivo de entrar DON QUIJOTE en el VIII año de su publicacion.

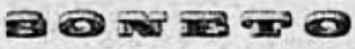 \\ artien-}

Tu que sufriste de carnero empacho, tu que azotaste al agio $\mathrm{y}$ al cohecho, tu, Sojo, á quien quisiera ver desecho algun advenedizo mamarracho; has dado a aDon Quijoten buen despacho, pues su campaña fué de honra y provecho siempre del pueblo defendiendo el derecho, idel pueblo que no tiene, pan, ni techo! - ¿Que patria es esta patria?-La del mocho, pues pobre se quedo teniendo mucho; cual en rico trocose un polve chocho cercenando hasta el aite de Ayroucho...... ¿De la riqueza pública, bizcocho exelente que resta? - Ya ni un pucho!

Urganda la civica.
«El Pavo»: Presidente Roque Sáenz Peña

«El Zorro»: Presidente Julio Argentino Roca

«El Burrito Cordobés»: Miguel Juárez Celman, cuñado de Roca y luego presidente de la Nación

«Cangrejo»: Presidente José Evaristo Uriburu. Entre otros tantos personajes.

Entre sus creativos se destacan el director y propietario de la publicación El Quijote, Eduardo Sojo, quien firmaba cómo Demócrito (I). Entre los dibujantes encontramos a José Sixto Álvarez Escolada como Fray Mocho, Manuel Mayol Rubio cómo Heráclito, José María Cao Luaces Demócrito (II). La prensa argentina considera a Cao como el padre de la caricatura política argentina.

Fig. 5- Detalle: Publicación Don Quijote, domingo 23 de agosto de 1891, Año VIII, páginas 2, en: Fondos y colecciones digitales - Manuscritos e impresos originales - Prensa y publicaciones periódicas, recuperado de: http://ravignanidigital.com.ar/ libros/quijote/Q10000000.html?a=8\&s=1\&ch=1 [consultado 2021].

Algunas publicaciones, como Don Quijote, representaban los principales políticos de ese momento con nombres de animales. Así por ejemplo: 


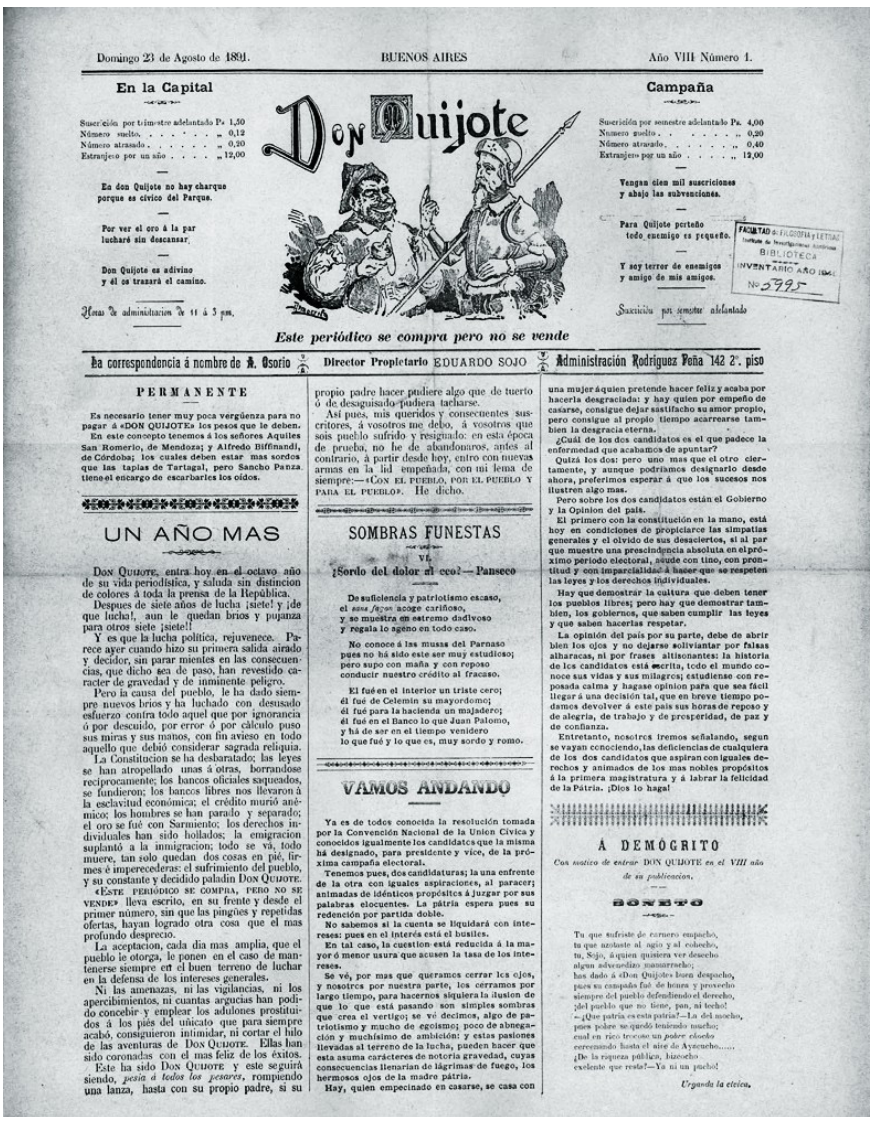

Fig. 6- Publicación Don Quijote. Domingo 23 de agosto de 1891, Año VIII, páginas 2. En la parte central de su cabecera se lee "este periódico se compra pero no se vende"en: Fondos y colecciones digitales - Manuscritos e impresos originales Prensa y publicaciones periódicas, recuperado de: http://ravignanidigital.com.ar/libros/quijote/Q10000000.html?a=8\&cs=1\&h=1 [consultado 2021], p. 2.

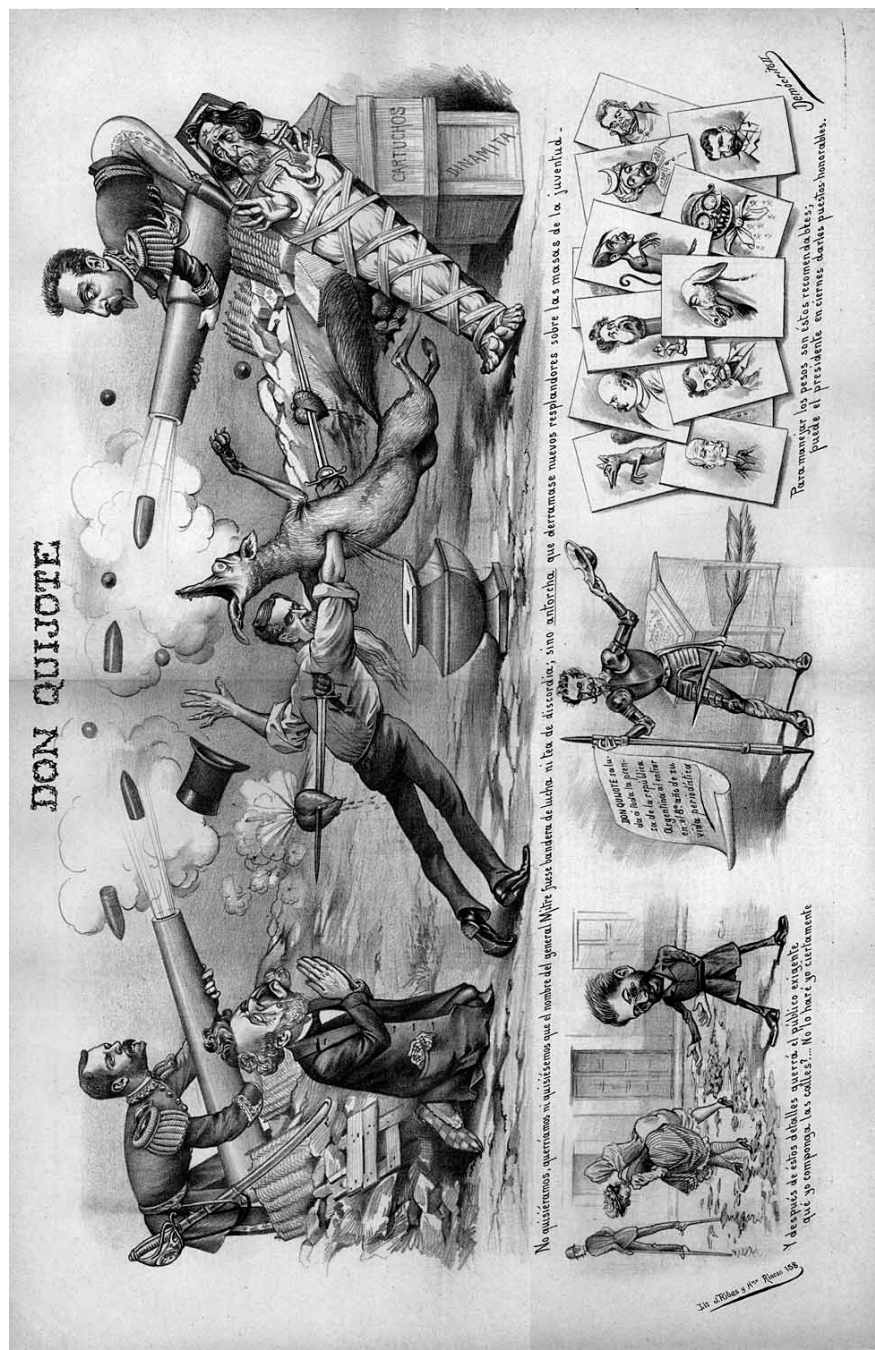

Fig. 7- Año VIII Nro. 1 del 23-Ago-1891, página 3 en: Fondos y colecciones digitales - Manuscritos e impresos originales - Prensa y publicaciones periódicas, recuperado de: http://ravignanidigital.com. ar/libros/quijote/Q10000000.html?a=8\&s=1\&ch=1 [consultado 2021], p. 3. 
Entre 1880 y 1890 fue un período de gran inestabilidad política y social que atravesó el país, producto por la fuerte crisis económica. La publicación El Quijote fue uno de los elementos determinantes que permitió, junto a la prensa en general, provocar una gran tensión entre la opinión pública y el sector político. Esto provocó una movilización (cívico-militar) que derrocó un gobierno, conocida como la Revolución del Parque en 1890, ocasionó que Juárez Celman renunciara a la presidencia de la nación.

Sin embargo, en 1894 la crisis social y económica en la Argentina no había desparecido. Ernesto de la Cárcova llevó al lienzo una de las grandes problemáticas de la época, y la que sin duda es una de sus más destacadas obras: Sin pan y sin trabajo, producción artística que representa la crisis social obrera. Sin pan y sin trabajo fue comenzada en Roma y terminada en Buenos Aires. Malosetti Costa ha realizado numerosos estudios, entre los que se destaca la crisis social en que se encuentran sus personajes. La representación alude a un hombre que observa a través de su ventana a un grupo de obreros de una fábrica cercana, los que son reprimidos por la policía a caballo, mientras se manifiestan a través de una huelga.

La temática de la obra pone énfasis

[...] en imágenes cuestiones tan nuevas como problemáticas, vinculadas al fenómeno de la inmigración masiva y la transformación de la ciudad en la que despuntaba una incipiente actividad industrial: la pobreza urbana, las luchas obreras, la represión y el llamado a la solidaridad social. (Malosetti Costa, 2007: 304)

Por lo tanto, y sin llegar a un análisis más profundo de la obra, podemos determinar que esta nos brinda información dentro del contexto histórico social de la época, estableciendo de este modo un marco concreto de la realidad.

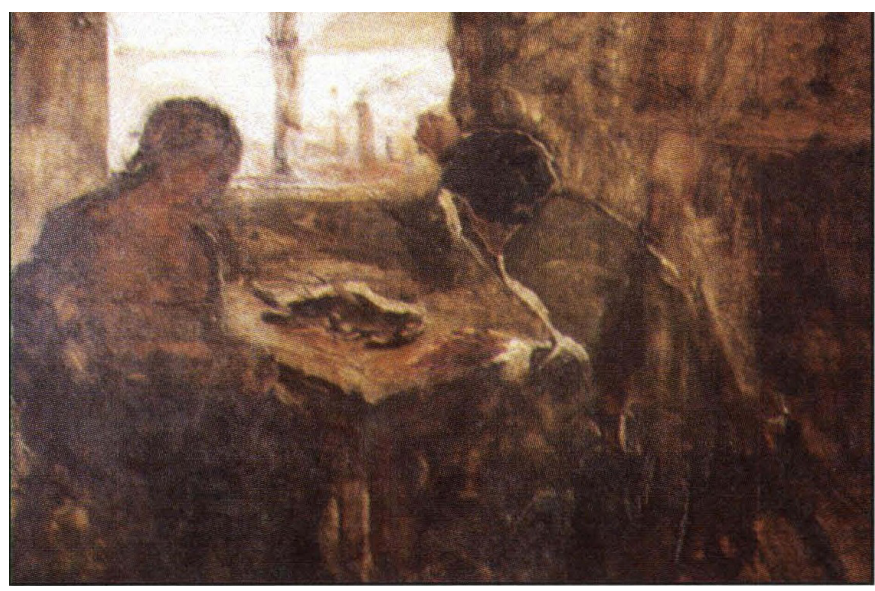

Fig. 8- Ernesto de la Cárcova. Boceto para Sin pan y sin trabajo, Colección particular, óleo sobre tabla. Recuperado de:

https://books.openedition.org/ifea/docannexe/ image/4476/img-7.jpg [consultado 2021].

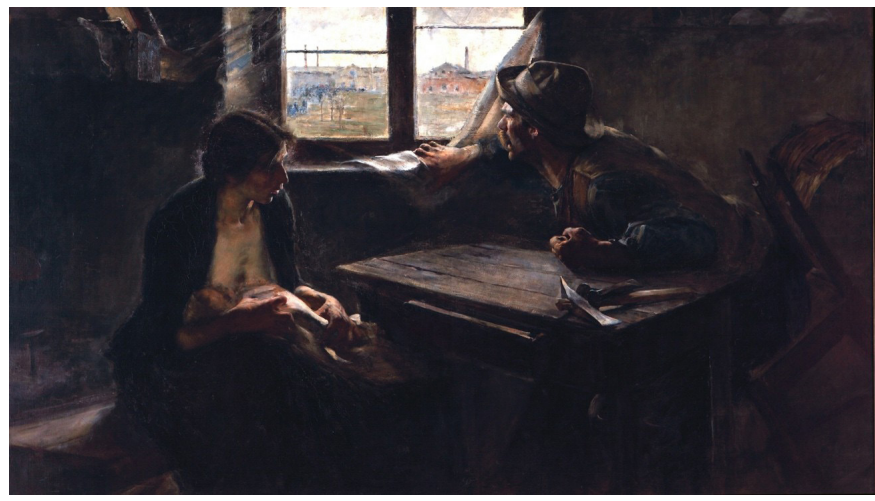


Fig. 9- Sin pan y si trabajo, Ernesto de la Cárcova 1894, en: Museo de Bellas Artes recuperado de: https://www.bellasartes.gob.ar/coleccion/ obra/1777/ [consultado 2021].

Sin pan y sin trabajo: Descripción de la obra: Museo Nacional de Bellas Artes

Autor: De la Cárcova, Ernesto Origen: (Argentina, Buenos Aires, 1866 - Argentina, Buenos Aires, 1927)

Fecha: 1894 Período: Arte siglo XIX Escuela: Argentina XIX

Técnica: Óleo Objeto: Pintura

Estilo: Naturalismo, realismo

Género: social Soporte: tela

Medidas: 125,5 X $216 \mathrm{~cm}$

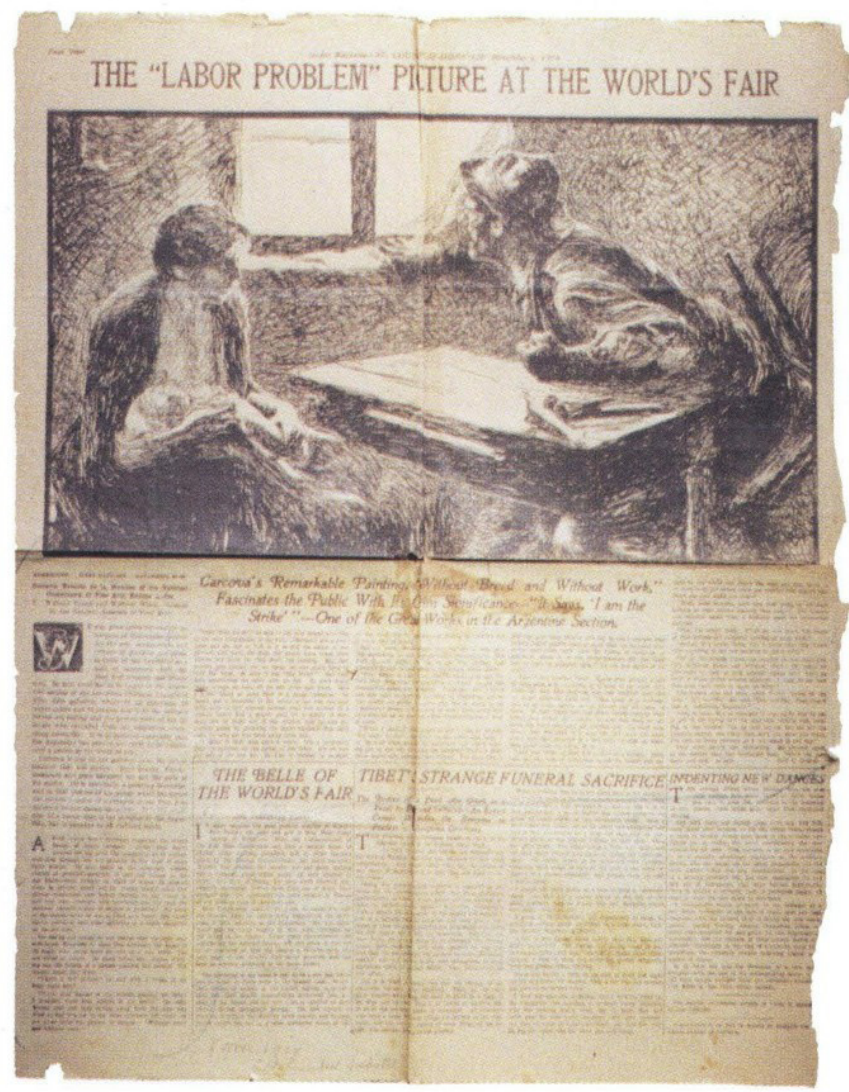

Fig. 10 - Malosetti Costa: St. Louis Post-Dispatch 6.XI.1904. Sunday Magazine recuperado de: https://books.openedition.org/ifea/docannexe/ image/4476/img-8.jpg [consultado 2021], p. 34.

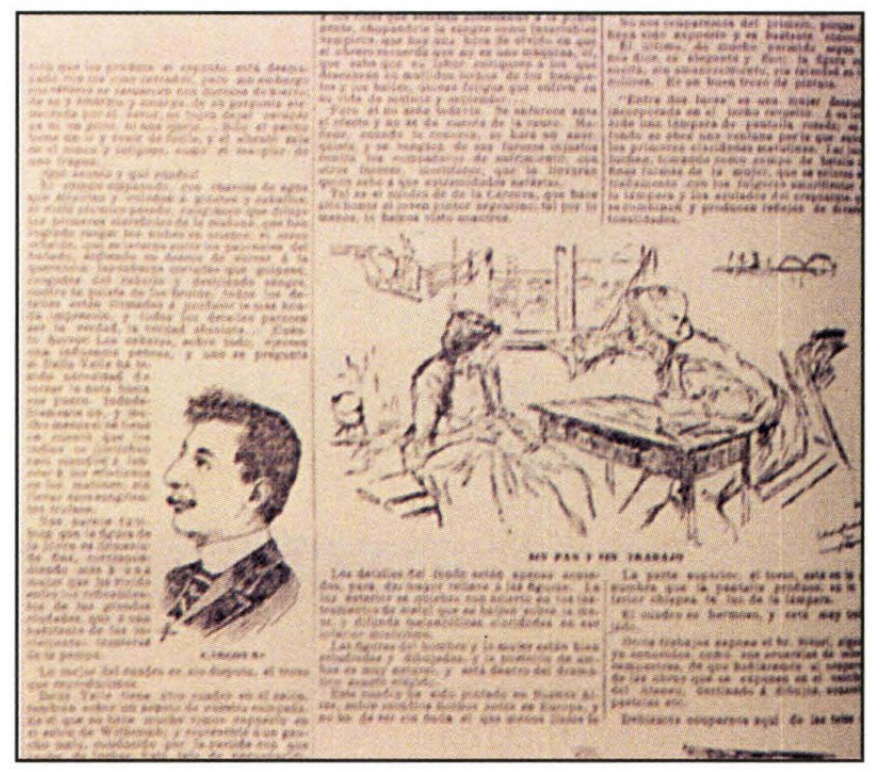

Fig. 11 - Malosetti Costa: Fragmento de artículo en La Nación. 3.XI.1894, p.5. Dibujo de Martín Malharro de Sin pan y sin trabajo y retrato de Ernesto dela Cárcova recuperado de: https://books. openedition.org/ifea/docannexe/image/4476/ img-8.jpg [consultado 2021], p. 31

\section{A modo de cierre}

Para el estudio de las narrativas históricas latinoamericanas consideramos que es necesario un abordaje (desde lo metodológico) integral e interdisciplinario, sin entrar en las dicotomías disciplinares entre la historia y la historia del arte. Por ello nuestra propuesta se orienta a lograr un abordaje reflexivo en torno al discurso histórico y visual en América Latina, dado que se encuentra 
“[...] anclado en lo cultural, lo representacional o capacidad de simbolización de los grupos humanos" (Peist Rojzman, 2014: 46).

De esta manera, comprendemos que estas narrativas se encuentran totalmente vinculadas a establecer una relación dialéctica entre los elementos visuales y las construcciones históricas desde un abordaje social. Por lo tanto, es sumamente importante el estudio de estas construcciones socio-culturales, las que se encuentran sustentadas a través de una materialidad simbólica, que hemos heredado a lo largo del tiempo. Por consiguiente nos permite un lugar para la discusión y la deliberación en un recorrido histórico que se construye desde nuevas formas discursivas con un sustento documental diferente.

\section{Referencias citadas}

Benjamin, W. (1998): Discursos ininterrumpidos I, Buenos Aires, Taurus.

Biblioteca Británica. Recuperado de: https://www. bl.uk/ [consultado 2021].

Bourdieu, P. (2010): El sentido social del gusto. Elementos para una sociología de la cultura, Buenos Aires, Siglo Veintiuno Editores.

Burke, P. (1996): Formas de Hacer Historia, Madrid, Alianza.

Burke, P. (2005): Visto y no visto. El uso de la imagen como documento histórico, Barcelona, Cultura libre.

Cano Vargas, A. (2012): “De la Historia de las Men- talidades a la Historia de los imaginarios sociales", Ciencias Sociales y Educación, 1 (1), pp. 135-146.

Chartier, R. (2003): Cultura Escrita, Literatura e Historia, México, Fondo de Cultura Económica.

Clark, T. J. (1981): Imagen del pueblo. Gustave Courbet y la Revolución de 1848, Barcelona, Gustavo Gili.

Durand, G. (1968): La imaginación simbólica, Buenos Aires, Amorrortu.

Giunta, A. (1996): América Latina en disputa. Apuntes para una historiografía del arte Latinoamericano, International Seminar Art Studies from Latin America, Instituto de Investigaciones Estéticas, UNAM and The Rockefeller, Foundation, Oaxaca, pp.1-5.

Hadjinicolaou, N. (1974): Historia del Arte y Lucha de Clases, México, Siglo Veintiuno.

Heinich, N. (2002): Sociología del Arte, Buenos Aires, Nueva Visión.

Jamenson, F. (1989): Documentos de la cultura, documentos de barbarie. La narrativa como acto socialmente simbólico, España, Gráfica Roger, 1989.

Le Goff, J. y Nora, P. (1974): Hacer la historia Vol. III, Barcelona, Laia.

Malosetti Costa, L., Siracusano, G. y Telesca, A. M. (1999): "Impacto de la moderna historiografía europea en la construcción de los primeros relatos de la historia del arte argentino", (In) disciplinas: estéticas e historia del arte en el cruce de los discursos, México, XXII Coloquio Internacional de Historia del Arte, Ins- 
tituto de Investigaciones Estéticas de la Universidad Autónoma de México, pp. 395-425.

Malosetti Costa, L. (2002): “Canon, estiloy modernidad en la historiografía artística argentina. De Eduardo Schiaffino a Romero Brest”, Anais do XXII Colóquio do CBHA, Porto Alegre, Comitê Brasileiro de História da Arte, pp. 1-12.

Malosetti Costa, L. (2003): “Sin pan y sin trabajo: Un cuadro de familia y miseria en el Buenos Aires de 1890", Familia y vida cotidiana en América Latina, siglos XVIII-XX, Lima: Institut franÇais d éstudes andines. Recuperado de: https://books.openedition. org/ifea/4476 [consultado 2021], pp. 51-92.

Malosetti Costa, L. (2007): Los primeros modernos. Arte y Sociedad en Buenos Aires a fines del siglo XIX, Buenos Aires, Fondo de Cultura Económica.

Peist Rojzman, N. (2014): "Historia del arte, estudios visuales y sociología del arte: un debate ideológico-disciplinar", MILLCAYAC Revista Digital de Ciencias Sociales, pp. 31-48.

Panosfky, E. (1983): El significado en las artes visuales, Madrid, Aliaza.

Román, C. (2010): “De la sátira impresa a la prensa satírica. Hojas sueltas y periódicas en la configuración de un imaginario político para el Río de La Plata (17791834)", Estudios. Revista de investigaciones literarias y culturales, 36, pp. 324-349.

Sánchez Delgado, P. (1993): De Annales en la enseñanza de la historia en España, Tesis Doctoral, Madrid, Universidad de Madrid.
Sosa, E. N. (2015): Vida y Muerte en Mendoza 17871923. El sincretismo cultural a través de la funebria mendocina, Mendoza,EDIFyL, FFyL, Universidad Nacional de Cuyo.

Sosa, E. N. (2019): "Imagen, miradas... tiempos y presencias", en Apuntes y reflexiones sobre las artes, las historias y las metodologías. Volumen 1, Santiago, Universidad Autónoma de Chile-RIL Editores, pp. 15-24.

Vovelle, M. (1985): Ideologías y Mentalidades, Barcelona,Ariel. 